\title{
Source characteristics, chemical weathering, and lithification of the Stimson sandstone and lessons for
}

the martian sedimentary record

\section{Kirsten Siebach, Liz Rampe, Shaunna Morrison}

The Stimson formation is a basaltic eolian sandstone perched unconformably above the Mount Sharp group rocks in Gale crater, and it is exposed in a number of plateaus observed by the Mars Science Laboratory Curiosity rover. Despite being one of the least geochemically and mineralogically diverse units observed by the Curiosity rover, the Stimson formation is uniquely positioned to offer significant information about sand weathering and lithification processes on Mars because of two factors: (1) the Stimson formation is the only lithologic formation on Mars for which we have a modern analog, the basaltic eolian Bagnold dunes, and (2) Curiosity obtained 33 chemistry analyses of 18 unique targets with the Alpha-Particle X-ray Spectrometer and 2 mineralogical samples of unaltered Stimson sandstone (discounting samples of Stimson altered by late-stage fluid events). Comparison between the Stimson sandstone and the Bagnold sands yields clues to source rock and lithification processes on Mars, and differences between different Stimson samples reveal weathering trends affecting the ancient dune field.

The source rocks for the Stimson sandstone compositionally approximate average Mars and may be very similar to the sources for the modern Bagnold dunes. Potential mineralogical differences between Stimson and Bagnold sources exist, particularly in different modeled pyroxene assemblages, but the angular resolution of CheMin is not sufficient to definitely establish those differences. The most dramatic differences between the Bagnold sand and the Stimson sandstone are likely related to lithification processes, and include a significant decrease in olivine ( $\sim 17 \mathrm{wt} \%$ to undetectable) and amorphous material, and an $\sim 12 \mathrm{wt} \%$ increase in crystalline iron oxides in the Stimson relative to Bagnold, which has been interpreted as evidence for olivine dissolution and iron oxide cementation. More subtle geochemical differences within the Stimson itself reveal a chemical weathering trend, where some Stimson samples show less anorthositic plagioclase, more secondary minerals, and a shift to more Mg-rich amorphous material. The Stimson provides a unique dataset for tracing geochemical contributions from source rocks, weathering processes, and lithification of a sedimentary formation on Mars. 